\title{
Coupling effects of water and nitrogen on photosynthetic characteristics, nitrogen uptake, and yield of sunflower under drip irrigation in an oasis
}

\author{
Tianyu Wang ${ }^{1,2}$, Zhenhua Wang ${ }^{1,2^{*}}$, Qiang $\mathrm{Wu}^{1,2}$, Jinzhu Zhang ${ }^{1,2}$, Lishuang Quan ${ }^{1,2}$, \\ Bihang Fan ${ }^{3 *}$, Li Guo ${ }^{3}$ \\ (1. College of Water Resources and Architectural Engineering, Shihezi University, Shihezi 832000, Xinjiang, China; \\ 2. Key Laboratory of Modern Water-saving Irrigation Corp, Shihezi University, Shihezi 832000, Xinjiang, China; \\ 3. State Key Laboratory of Hydraulics and Mountain River Engineering, College of Water Resource and Hydropower, \\ Sichuan University, Chengdu 610065, China)
}

\begin{abstract}
An experiment was conducted in an oasis area in northwest China to assess the coupling effects of water and nitrogen supply through drip irrigation on photosynthetic characteristics, nitrogen uptake, and yield of sunflower (Helianthus annuus L.), as well as the nitrate distribution in the root-zone soil. The experiment included three irrigation levels $(210$ [W1], 300 [W2], and 390 [W3] mm), three nitrogen levels (162 [N1], 232 [N2], and 302 [N3] kg/hm²), and control treatment (no fertilization during whole growth period and only irrigated at the budding stage). A nitrogen content over-accumulation in the soil was observed under the low irrigation amount with high fertilizer supply, which cannot enhance the sunflowers' absorption of nitrogen. Excessive irrigation caused leach of the soil nitrogen, reduced nitrogen content in the root-zone soil $(0-40 \mathrm{~cm})$ and limited nitrogen uptake by the crop. Although low irrigation amount with high fertilizer supply can increase the nitrogen content in the soil, it cannot enhance the sunflowers' absorption of nitrogen. At the vegetative stage of sunflower growth, the accumulation of nitrogen in the organs was mainly concentrated in the leaves, while it was transferred to the flower disk at the reproductive growth stage. Reasonable coupling of water and nitrogen improved the transport of nitrogen from leaves and stems to the flower disk and promoted the formation of yield components. Six regression equations were established with irrigation and fertilization amount as independent variables, and seed rate, seed weight per flowerdisk, 1000 grain weight, yield, water use efficiency and nitrogen partial factor productivity as dependent variables, respectively. Multiple regression and spatial analysis suggested that the irrigation amount of 241.62$253.35 \mathrm{~mm}$ and the fertilization application of $202.02-209.40 \mathrm{~N} \mathrm{~kg} / \mathrm{hm}^{2}$ was a good irrigation strategy, under which all six factors exceed $75 \%$ of their maxima, and the yield of sunflower reached $3229.3 \mathrm{~kg} / \mathrm{hm}^{2}$.
\end{abstract}

Keywords: fertilization, Helianthus annuus L., irrigation management, nitrogen transformation, nutrient uptake, Xinjiang DOI: $10.25165 /$ j.ijabe.20211405.6399

Citation: Wang T Y, Wang Z H, Wu Q, Zhang J Z, Quan L S, Fan B H, et al. Coupling effects of water and nitrogen on photosynthetic characteristics, nitrogen uptake, and yield of sunflower under drip irrigation in an oasis. Int J Agric \& Biol Eng, 2021; 14(5): 130-141.

\section{Introduction}

Sunflower (Helianthus annuus L.) is second only to soybeans in terms of global importance as an oil crop. Given its ability to adapt to various environments and climates, sunflower is widely planted even in many semi-arid and arid areas, such as the midwestern $\mathrm{USA}^{[1]}$, the Mediterranean region ${ }^{[2]}$, northeastern India $^{[3]}$, and northwestern China ${ }^{[4,5]}$. Sunflower is often supplied with large amounts of water and fertilizer to yield high-quality oil ${ }^{[6]}$.

\section{Received date: 2021-01-03 Accepted date: 2021-06-23}

Biographies: Tianyu Wang, $\mathrm{PhD}$, research interest: irrigation and water conservancy project, Email: 15963100756@163.com; Qiang Wu, PhD, research interest: water saving irrigation, Email: wuqianghlj@163.com; Jinzhu Zhang, $\mathrm{PhD}$, Associate Professor, research interest: irrigation and water conservancy project, Email: xjshzzjz@sina.cn; Lishuang Quan, Master candidate, research interest: agricultural planting management, Email: 281927102@qq.com; Li Guo, $\mathrm{PhD}$, Professor, research interest: soil-water and ecological hydrology, Email: liguo01@scu.edu.cn.

*Corresponding authors: Zhenhua Wang, PhD, Professor, research interest: theory and technology of water saving irrigation. Shihezi University, Shihezi 832000, Xinjiang, China. Tel: +86-993-2058979, Email: wzh2002027@ 163.com; Bihang Fan, PhD, Associate Professor, research interest: water resources management, Sichuan University, Chengdu 610065, Sichuan, China. Tel: +86-28-85045055, Email: fanbh@scu.edu.cn.
However, excessive application of chemical fertilizer will cause water pollution and increase production costs. Thus, increasing the efficiency of water and fertilizer application is essential for the regional environment and sunflower cultivation in arid areas ${ }^{[7]}$.

Sunflower is the most important oil-bearing crops in Xinjiang, China, which accounts for more than $60 \%$ of the total oil-bearing crop planting area. Irrigation management and nitrogen supply, including the rate, timing, and method of supply, strongly affect the yield and quality of sunflower ${ }^{[8,9]}$. In China, most sunflowers are watered with flood irrigation ${ }^{[10]}$. However, drip irrigation has proven superior to furrow irrigation because of its ability to save water and reduce nutrient leaching, especially in arid environments ${ }^{[11-13]}$. Xinjiang has an arid desert climate, the average annual rainfall in this area is only $150-200 \mathrm{~mm}$, but the evaporation is as high as $1000-4500 \mathrm{~mm}^{[14]}$. This leads to a shortage of fresh water resources in the region, especially during the crop growing season (May-October). It is necessary to popularize drip irrigation to sunflower planting. Sahoo et al. ${ }^{[15]}$ showed that compared with furrow irrigation, drip irrigation could improve the water use efficiency (WUE) and seed yield of sunflower. Improved irrigation and nitrogen use efficiency can be achieved through drip irrigation by adjusting the irrigation schemes according to the local environment ${ }^{[16]}$. Therefore, exploring the 
suitable drip irrigation and fertilization scheme for sunflower planting in Xinjiang will help to guide the local agricultural production.

Previous papers have studied the impact of irrigation strategies and fertilization schedules on sunflower under drip irrigation in various regions. Sezen et al. ${ }^{[17]}$ studied the effects of different irrigation strategies on sunflower under a drip system and found that the oil contents of sunflower increased with increasing irrigation amounts. Elnaz et al. ${ }^{[18]}$ also found that the seed yield and oil yield of sunflower decreased by $16.2 \%$ and $22.3 \%$ when irrigation water was lacking. The duration of water stress and the timing during different growth stages of sunflower influence the growth and yield of the crop. For example, if no irrigation was applied in the early growth stage but started when miniature floral head appeared, the sunflower yield was only reduced by $6 \%^{[10]}$. Karam et al. ${ }^{[19]}$ showed that irrigation deficits in the early- and mid-flowering stages reduced seed yield, but irrigation deficit during early seed formation could raise seed yield.

Nitrogen $(\mathrm{N})$ fertilizer is an important yield limiting factor for sunflower production ${ }^{[20]}$. Gul and Kara ${ }^{[21]}$ indicated that although the effects of nitrogen on sunflower oil content were irregular, nitrogen had a positive effect on sunflower seed yield. Kara ${ }^{[22]}$ found that nitrogen fertilizers applied at the time of sowing had a stronger effect on the agronomic traits of sunflower than fertilizer application at the time of flowering and plate formation. Achieving a beneficial balance of water and nitrogen application is essential to make the best use of drip irrigation as well as crop growth and yield ${ }^{[23-25]}$. Careful regulation of nitrogen and water under drip irrigation not only improves crop yields and oil quality in sunflowers but also decreases the leaching of nitrogen into groundwater $^{[26-28]}$.

However, the impact of the interaction between water and nitrogen under drip irrigation on sunflower growth remains largely uninvestigated, and the nitrogen distribution in soil and crop has rarely been monitored. The accumulation and translocation of nitrogen in sunflower have not been analyzed. An irrigation scheme based on the comprehensive consideration of quality, yield, and water and fertilizer utilization efficiency of sunflower is still lacking. A field experiment was conducted in an oasis agroecosystem in Xinjiang, China to evaluate the effects of practicing drip irrigation on photosynthesis, $\mathrm{WUE}_{\mathrm{ins}}$, production, and total nitrogen uptake of sunflower under three irrigation levels and three nitrogen supply levels. In addition, the distribution of soil nitrates under these different combinations in the root zone was examined. This study clarifies the optimal management protocols for sunflower production under drip irrigation in arid environments, thus providing valuable information to boost yields while reducing production costs and fertilizer pollution in similar areas.

\section{Methods and materials}

\subsection{Experiment site}

A field experiment was conducted in 2014 and 2015 at the Key Laboratory of Modern Water-Saving Irrigation of Xinjiang Production and Construction Corps of Shihezi University $\left(85^{\circ} 59^{\prime} \mathrm{E}\right.$, $44^{\circ} 19^{\prime} \mathrm{N}, 412 \mathrm{~m}$ a.s.1.). The area of the experimental plot is $0.06 \mathrm{hm}^{2}$, and the regional groundwater level is deeper than $8 \mathrm{~m}$. The average annual sunshine duration at the study site is $2865 \mathrm{~h}$, and the accumulated air temperature above $10^{\circ} \mathrm{C}$ and above $15^{\circ} \mathrm{C}$ is $3463.5^{\circ} \mathrm{C}$ and $2960.0^{\circ} \mathrm{C}$, respectively, with an average frost-free period of $170 \mathrm{~d}$. The average annual rainfall and potential evaporation are $207 \mathrm{~mm}$ and $1660 \mathrm{~mm}$, respectively. Before the experiment, we randomly selected five points in the test area and measured soil particle composition, soil type, bulk density, $\mathrm{pH}$, total nitrogen, nitrate-nitrogen, and soil organic matter at each depth (Table 1).

Table 1 Physical and chemical properties of 0-100 $\mathrm{cm}$ soil before the experiment

\begin{tabular}{|c|c|c|c|c|c|c|c|c|c|}
\hline \multirow{2}{*}{ Soil depth/cm } & \multicolumn{3}{|c|}{ Soil particle composition $/ \mathrm{g} \cdot \mathrm{kg}^{-1}$} & \multirow{2}{*}{ Texture } & \multirow{2}{*}{$\begin{array}{l}\text { Bulk density } \\
\quad / \mathrm{g} \cdot \mathrm{cm}^{-3}\end{array}$} & \multirow{2}{*}{$\mathrm{pH}$} & \multirow{2}{*}{$\begin{array}{l}\text { Total N } \\
/ \mathrm{mg} \cdot \mathrm{kg}^{-1}\end{array}$} & \multirow{2}{*}{$\begin{array}{l}\text { Nitrate-N } \\
/ \mathrm{mg} \cdot \mathrm{kg}^{-1}\end{array}$} & \multirow{2}{*}{$\begin{array}{c}\text { Soil organic matter } \\
\qquad / \mathrm{g} \cdot \mathrm{kg}^{-1}\end{array}$} \\
\hline & $<0.002 \mathrm{~mm}$ & $0.002-0.02 \mathrm{~mm}$ & $0.02-2 \mathrm{~mm}$ & & & & & & \\
\hline $0-20$ & 113 & 683 & 212 & Silty loam & 1.455 & 7.71 & 352.2 & 15.602 & 1.49 \\
\hline $20-40$ & 126 & 716 & 186 & Silty loam & 1.525 & 7.96 & 215.9 & 16.738 & 2.59 \\
\hline $40-60$ & 193 & 581 & 53 & Silty loam & 1.565 & 7.83 & 150.15 & 11.201 & 2.19 \\
\hline $60-80$ & 220 & 653 & 50 & Silty loam & 1.650 & 7.18 & 116.00 & 9.097 & 1.47 \\
\hline $80-100$ & 207 & 705 & 51 & Silty loam & 1.645 & 7.74 & 183.64 & 8.250 & 1.91 \\
\hline
\end{tabular}

\subsection{Experimental design}

The experiment was established in a randomized complete block design in a factorial approach with different combinations of irrigation $(\mathrm{W})$ and nitrogen $(\mathrm{N})$ treatments delivered through a drip irrigation system. A common local sunflower variety, the early-maturing cultivar "Xinkuizi V", was planted in both two years. Sowing dates were $12 / 7 / 2014$ and $14 / 7 / 2015$, and the harvest dates were 10/10/2014 and 12/10/2015. According to the sunflower planting habits of local farmers, the irrigation amount is usually more than $350 \mathrm{~mm}$ in a growth period, and the amount of nitrogen fertilizer is generally about $280 \mathrm{~kg} / \mathrm{hm}^{2}$. It's generally high, which may lead to a waste of water and fertilizer. In addition, in our previous work, by separately studying the water and nitrogen requirement of the same variety of sunflower, it was found that the suitable irrigation amount and nitrogen supply of sunflower with drip irrigation in this area are 285.2-287.7 mm and 187.9-243.6 kg/hm ${ }^{2}$, respectively ${ }^{[29,30]}$. To comprehensively analyze the interaction effects of water and nitrogen on sunflower, find the most suitable irrigation and fertilization strategy, and improve the utilization efficiency of water and fertilizer, a range based on previous research and local habits was designed. Therefore, three irrigation levels were designed: 210 (W1), 300 (W2), and 390 (W3) mm. The nitrogen supply also had three levels: $162(\mathrm{~N} 1), 232(\mathrm{~N} 2)$, and $302(\mathrm{~N} 3) \mathrm{kg} / \mathrm{hm}^{2}$. With each irrigation level being paired with each nitrogen level, a total of nine treatments $(3 \times 3)$ were applied. In addition, we chose a rain-fed sunflower field as the control check (CK), which was irrigated only at the budding stage, while no irrigation and fertilization were applied for the rest of the sunflower growth period. Urea [CO $\left(\mathrm{NH}_{2}\right)_{2}$; nitrogen content of $46.4 \%$ by mass] was applied as the nitrogen fertilizer at the determined levels at the same time of irrigation. The irrigation and fertilizer date, and the meteorological data of the experimental area during the sunflower growth periods are shown in Figure 1. Climatic conditions of both experimental years were close. According to our previous research on crop water requirement ${ }^{[29]}, 6$ times of irrigation was 
carried out during the whole growth period of sunflower, the water-soluble fertilizer was added into irrigation system and entered the field in each irrigation. A detailed record of water and nitrogen applications, grouped by growth stage and treatment, is shown in Table 2. $165 \mathrm{~kg} / \mathrm{hm}^{2}$ of Potassium dihydrogen phosphate $\left[\mathrm{KH}_{2} \mathrm{PO}_{4}\right]$ as the phosphate and potash fertilizer for all treatments, was applied in the first irrigation at one time.

Irrigation was performed with drip tapes that were $16 \mathrm{~mm}$ in external diameter with a $0.3 \mathrm{~mm}$ wall thickness and the dripper spacing of $30 \mathrm{~cm}$, with no plastic film mulched, capable of delivering $1.2 \mathrm{~L} / \mathrm{hm}^{2}$ at the operating pressure of $60 \mathrm{kPa}$. The non-pressure compensating, inline labyrinth-channel dripper, was used. Prior to the planting of sunflower, the drip tape was laid on the midline of the north-south-oriented soil beds with a spacing of $0.6 \mathrm{~m}$. Sunflower seeds were hand-planted in early July at a density of approximately 83000 plants $/ \mathrm{hm}^{2}$. All sunflowers were planted in rows along the drip lines with $25 \mathrm{~cm}$ between plants. Each treatment was replicated in three plots $(4.5 \mathrm{~m}$ wide $\times 18.6 \mathrm{~m}$ long). A schematic representation of the experimental setup is shown in Figure 2.

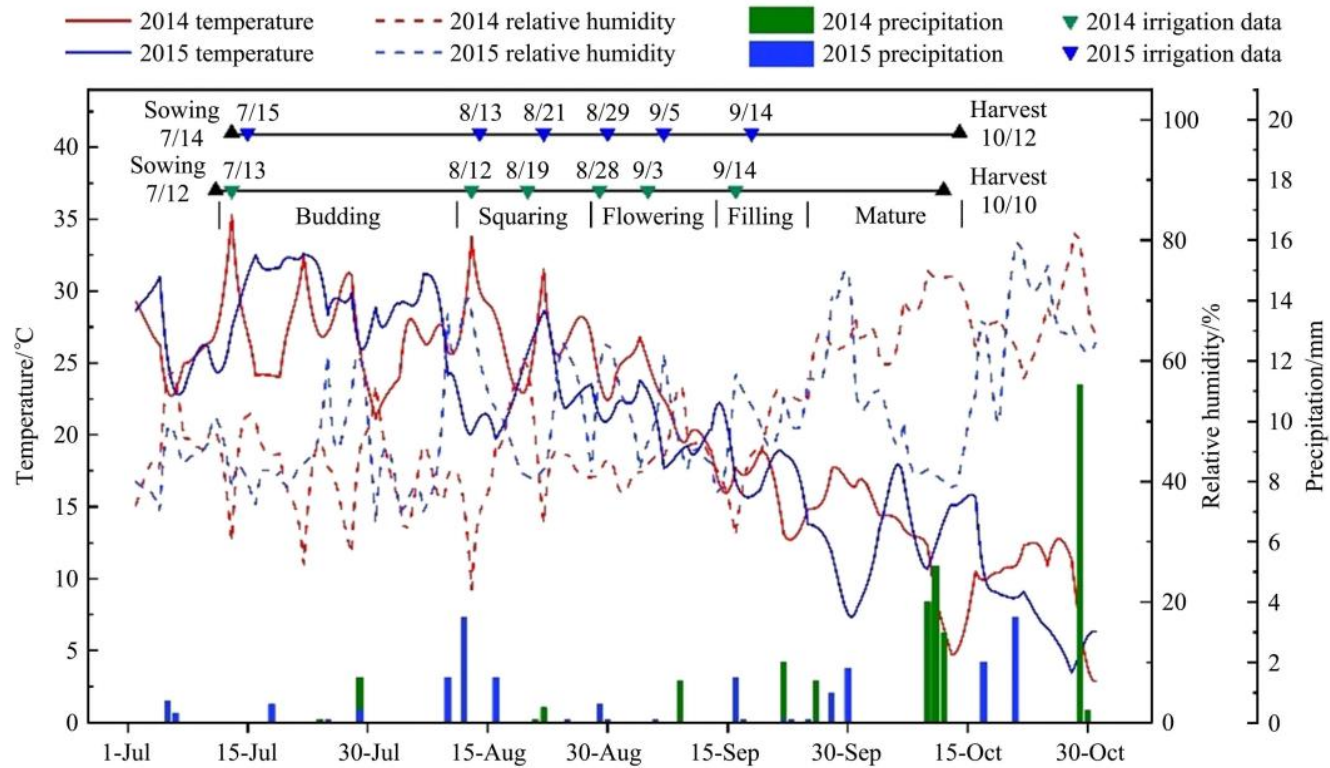

Figure 1 Daily meteorological variation and field management information during sunflower growth periods (July to October) in 2014 and 2015

Table 2 Irrigation and fertilizer treatments in the experiment

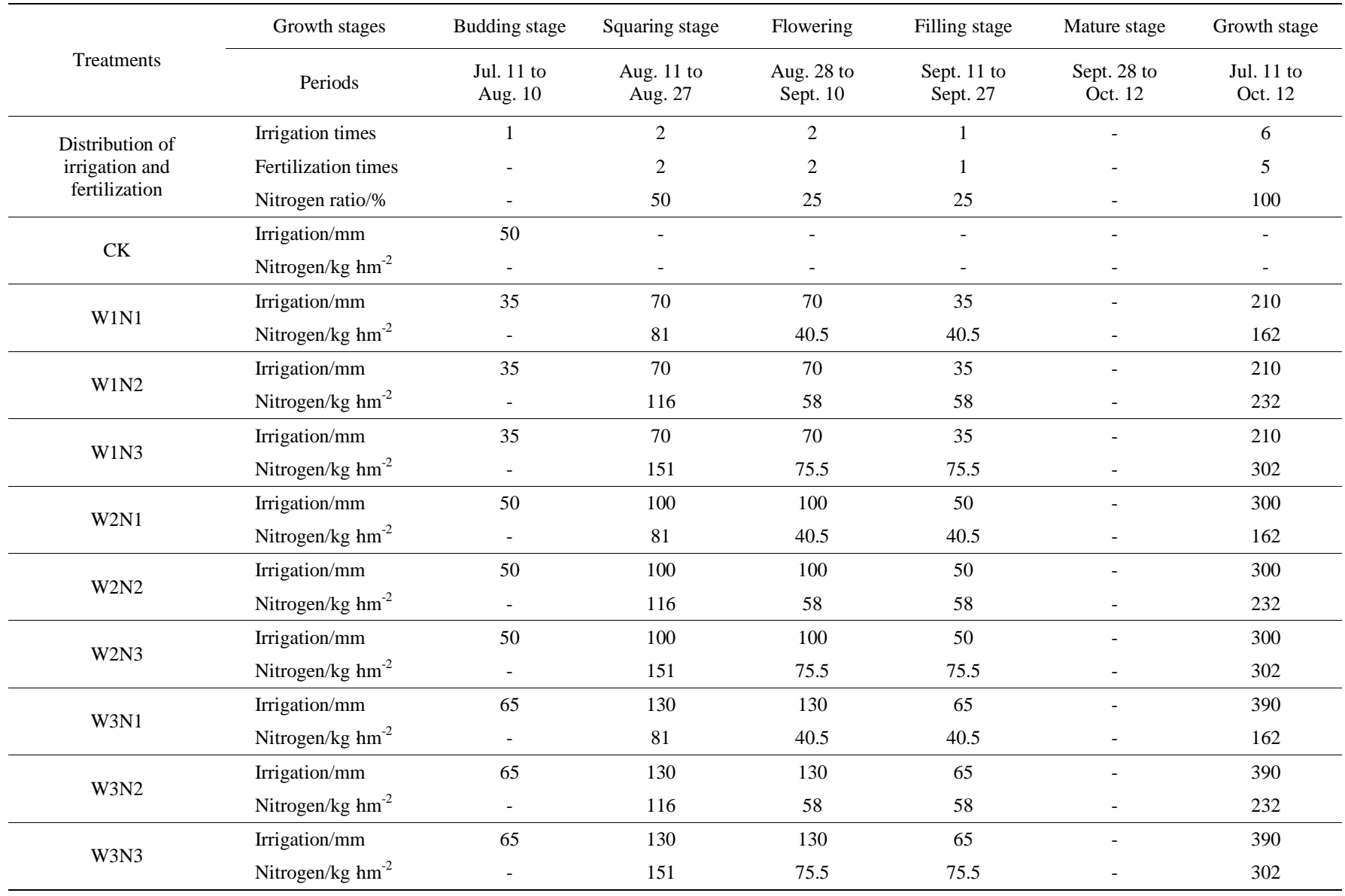




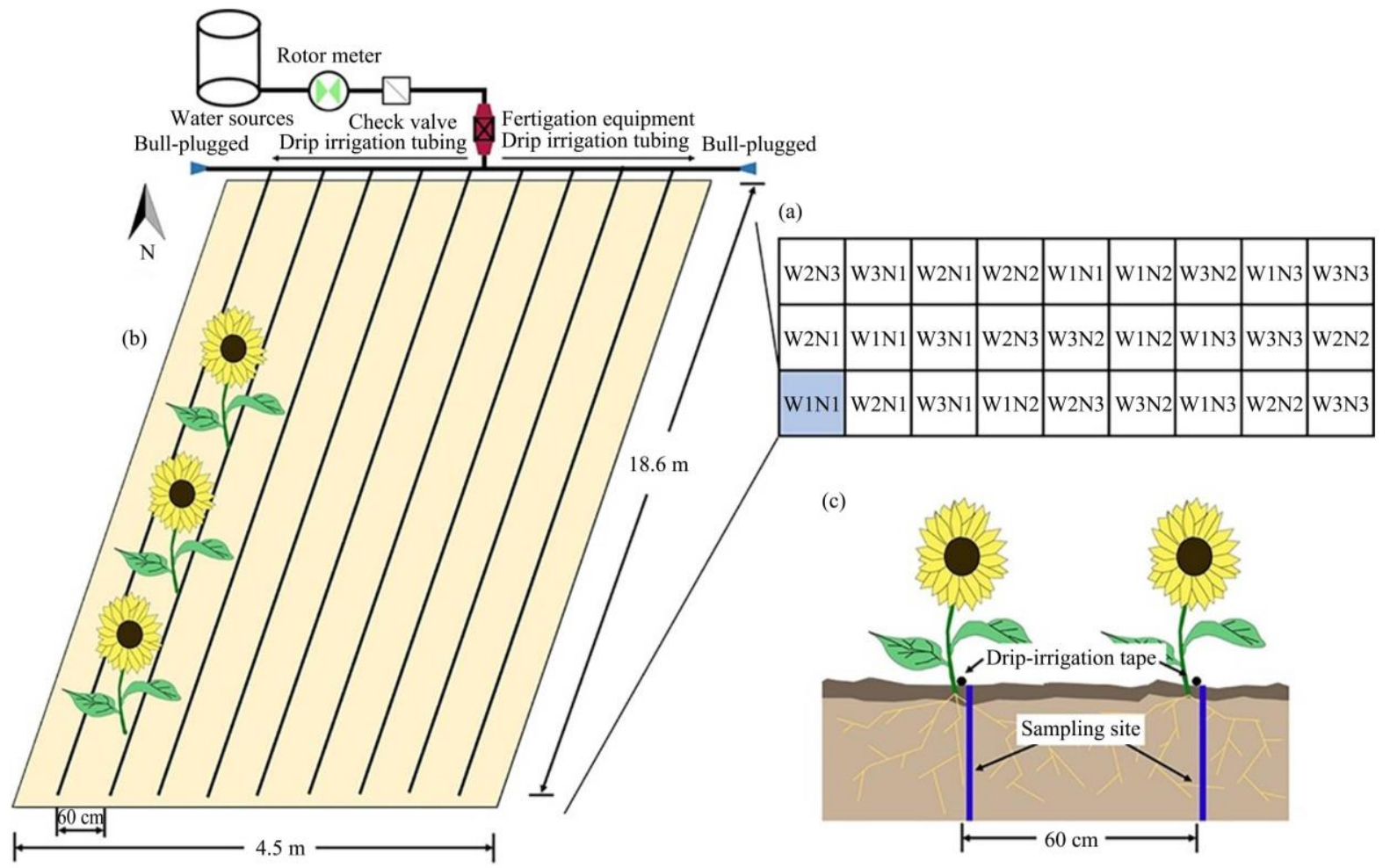

Note: (a) shows the experimental plot distribution under three levels of irrigation (W1, W2, W3) and nitrogen (N1, N2, N3), with three replicates. (b) is a diagram of the W1N1 treatment under drip irrigation, showing the system and its size. (c) provides a profile view of the cultivation pattern of the drip-irrigated sunflower used in this study, with sampling locations depicted.

Figure 2 Depiction of the water-nitrogen coupling experimental design

\subsection{Sampling and measurements}

Soil samples were taken at $1 \mathrm{~m}$ depth before sowing and again at the end of seedling, squaring, flowering, filling, and mature stages for the analysis of total nitrogen and nitrate nitrogen. The soil cores were taken with a $3 \mathrm{~cm}$ diameter semi-cylindrical auger. Three duplicate cores were taken from random positions within each plot under the drip tape and directly between two plants. The soil samples were split into four depth intervals: 0-20, 20-40, $40-60$, and $60-80 \mathrm{~cm}$. The total nitrogen contents were extracted by shaking $40 \mathrm{~g}$ of fresh soil with $100 \mathrm{~mL}$ of $\mathrm{KCl}$ solution for $2 \mathrm{~h}$. The resulting slurry was settled for 30 min and was then filtered (sieve pore diameter $1 \mathrm{~mm}$ ). The solution was analyzed for nitrate-nitrogen with an AMS SmartChem140 Analyzer (Alliance, Italy). Concentrations $(\mathrm{mg} / \mathrm{L})$ in the extracted solution were converted to field units of $\mathrm{kg} / \mathrm{hm}^{2}$ by the value of soil bulk density measured in advance (Table 1).

Five random plants per treatment were sampled at 7-10 day intervals to measure dry matter during different sunflower growth stages (squaring, flowering, filling, and mature stages). Dry matter was weighted after the samples were oven-dried at $105^{\circ} \mathrm{C}$ for $1 \mathrm{~h}$ and then at $80^{\circ} \mathrm{C}$ to a constant weight. Total nitrogen and nitrate-nitrogen in the sunflower leaves, stem, and flower disk were determined from oven-dried, milled samples by using the Dumas combustion method with a Leco Nitrogen Analyzer ${ }^{[31]}$.

After the seedling stage, the photosynthetic characteristics of sunflower under natural atmospheric condition were measured every ten days between 9:00 and 11:00 (local time) by using a handheld photosynthesis system (CI-340, CID, USA). The air temperature was $27-31^{\circ} \mathrm{C}$, light intensity was $800-1000 \mu \mathrm{mol} / \mathrm{m}^{2} \cdot \mathrm{s}$, and $\mathrm{CO}_{2}$ concentration was $350-360 \mu \mathrm{mol} / \mathrm{mol}$. Three readings were taken for each parameter on the fully expanded leaves of the plants. These readings of photosynthetic physiological characteristics included net photosynthetic rate $(P n)$ and transpiration rate $(T r)$, as well as environmental factors such as photosynthetically active radiation (PAR), air temperature $(\mathrm{Ta})$, and $\mathrm{CO}_{2}$ concentration in the air. On the basis of these measurements, $\mathrm{WUE}_{\text {ins }}$ was calculated as:

$$
\text { WUEins }=P n / T r
$$

At harvest, sunflower plants from the inner $1 \mathrm{~m} \times 1 \mathrm{~m}$ in the middle row of each plot were collected for analysis. Aboveground biomass, seed yield, thousand-grain weight, and seed weight per flower disk (including empty seed husks) were recorded. The setting percentage was calculated as the ratio of the number of available seeds to the total number of seeds per flower disk. Then, the sunflower yield in the whole plot was recorded, which was converted into yield per hectare.

\subsection{Quantification of $\mathrm{N}$ in crop and soil}

The absolute accumulation of soil $\mathrm{N}\left(S_{A}, \mathrm{~kg} / \mathrm{hm}^{2}\right)$ was calculated as:

$$
S_{A}=h \gamma S / 10
$$

where, $h$ is the depth of soil, $\mathrm{cm} ; \gamma$ is the soil bulk density, $\mathrm{g} / \mathrm{cm}^{3}$; and $S$ is the contents of soil nitrogen, $\mathrm{mg} / \mathrm{kg}$.

The accumulation of total nitrogen $\left(M_{N}, \mathrm{~g} /\right.$ plant $)$ in different plant organs (leaves, stem, or flower disk) was calculated as:

$$
M_{N}=D C / 100
$$

where, $D$ is the quantity of dry matter in a specific organ, $\mathrm{g} / \mathrm{plant}$; and $C$ is the total nitrogen concentration in that organ, $\%$. The transportation of total nitrogen $(T, \mathrm{~g} / \mathrm{plant})$ was calculated as:

$$
T=M_{F N}-M_{M N}
$$

where, $M_{F N}$ is the accumulation of the total nitrogen in the different organs in the flowering stage, g/plant; while $M_{M N}$ is the accumulation of total nitrogen in the mature stage, g/plant. The ratio of transportation at mature stage $\left(P_{T}, \%\right)$ was calculated as:

$$
P_{T}=M_{T} / M_{F N} \times 100 \%
$$

where, $M_{T}$ is the mass of the total nitrogen transportation per organ, $\mathrm{g} / \mathrm{plant}$. The total nitrogen distribution ratio at mature stage $\left(P_{D}, \%\right)$ was calculated as: 


$$
P_{D}=M_{S N} / M_{P N} \times 100 \%
$$

where, $M_{S N}$ is the accumulation of total nitrogen in one organ, $\mathrm{g} /$ plant; and $M_{P N}$ is the accumulation of total nitrogen in a plant, $\mathrm{g} /$ plant. The amount of total nitrogen accumulated in the flower disks $\left(M_{F I N}, \mathrm{~g} /\right.$ plant $)$ was calculated as:

$$
M_{F I N}=M_{F M N}-M_{F F N}
$$

where $M_{F M N}$ is the accumulation of total nitrogen in the flower disk at maturity, g/plant; and $M_{F F N}$ is the accumulation of total nitrogen in the flower disk at flowering, g/plant.

\subsection{Irrigation water, fertilizer utilization efficiency and regression equation}

The irrigation water utilization efficiency $(i W U E)\left(\mathrm{kg} / \mathrm{m}^{3}\right)$ was calculated as ${ }^{[32]}$ :

$$
i W U E=Y / I
$$

where, $Y$ is the sunflower yield, $\mathrm{kg} / \mathrm{hm}^{2}$; and $I$ is the irrigation water amount, $\mathrm{m}^{3} / \mathrm{hm}^{2}$. The nitrogen partial factor productivity $\left(N_{P F P}\right)$ $(\mathrm{kg} / \mathrm{kg})$ was calculated as:

$$
N_{P F P}=Y / N_{T}
$$

where, $Y$ is the sunflower yield, $\mathrm{kg} / \mathrm{hm}^{2}$; and $N_{T}$ is the nitrogen application rate.

Some studies have demonstrated that the effect of water fertilizer binary factors on yield can be fitted by binary quadratic regression equation ${ }^{[25,33,34]}$

$$
z=z_{0}+a x+b y+c x^{2}+d y^{2}+f x y
$$

In order to further analyze the relationship between different factors, the fitting results were normalized by

$$
X_{\text {Norm }}=\left(X-X_{\min }\right) /\left(X_{\max }-X \text { min }\right)
$$

where, $X_{\text {norm }}$ is the normalized value (range $0-1$ ); $X$ is the raw data that needs to be normalized; and $X_{\min }$ and $X_{\max }$ denote the minimum and maximum value of the original data.

\subsection{Statistical analysis}

The value of each indicator (nitrate distribution and accumulation, net photosynthesis, transpiration rate, $\mathrm{WUE}_{\mathrm{ins}}$, nitrogen transportation and accumulation in sunflower organs and yield components) has passed the Shapiro-Wilk normality test and Homogeneity of variance test, and there is no significant difference between the two years $(p>0.05)$. The value of each indicator is the average of the data for 2014 and 2015. Given that the numerical results of each measurement item of $\mathrm{CK}$ are significantly lower than those of other treatments, to prevent our judgment of water nitrogen coupling effect from being affected, the analysis of variance (ANOVA) was performed only for the other nine treatments except CK. The IBM SPSS 19 (IBM, USA) package was used to conduct the normality test, Homogeneity of variance test, and the ANOVA tests on the experimental results. The Duncan test was performed to conduct multiple comparisons to examine the significant difference between the means of different treatments. Differences were considered statistically significant when $p<0.05$.

\section{Results}

\subsection{Effects of irrigation and $\mathrm{N}$ levels on soil nitrogen change}

\subsubsection{Dynamic distribution of nutrients in the soil profile}

The dynamic distribution of soil nitrate content during the whole growth period is shown in Figure 3. The variation of nitrate content in different soil depths was basically the same, which increased at first, reached the maximum at the flowering stage, and then decreased. This is because the nitrogen fertilizer was applied mainly in the squaring and flowering stages. For all treatments, the lowest concentration range is $4.99 \mathrm{mg} / \mathrm{kg}$ and the highest concentration range is $85.58 \mathrm{mg} / \mathrm{kg}$. The content of nitrate-nitrogen showed a downward trend with soil depth, and the content of nitrate nitrogen in $0-40 \mathrm{~cm}$ soil depth was higher than that in $40-80 \mathrm{~cm}$ in each treatment. At the soil depth of $20 \mathrm{~cm}$ and $40 \mathrm{~cm}, \mathrm{~W} 1 \mathrm{~N} 3$ was basically always at a high level. This was due to the minimum leaching effect of low irrigation on nitrate-nitrogen under high nitrogen application, which led to the accumulation of nitrate-nitrogen in the surface soil. At the soil depth of 60 and $80 \mathrm{~cm}, \mathrm{~W} 3 \mathrm{~N} 3$ was basically always at a high level. This was due to the leaching effect of high irrigation amount under high nitrogen application, which made the nitrate-nitrogen move to deep soil. A comparison of three irrigation levels showed that under the same irrigation condition, the distribution of nitrate-nitrogen in the $0-40 \mathrm{~cm}$ and $40-80 \mathrm{~cm}$ soil layers increased with the increase in nitrogen application. However, compared with the three fertilization levels, under the same nitrogen application, as the irrigation amount increased, the distribution of nitrate-nitrogen at only $0-40 \mathrm{~cm}$ showed a downward trend during the sunflower growth period, whereas that at $40-80 \mathrm{~cm}$ showed no obvious downward trend, which was less affected by irrigation amount and was relatively stable.

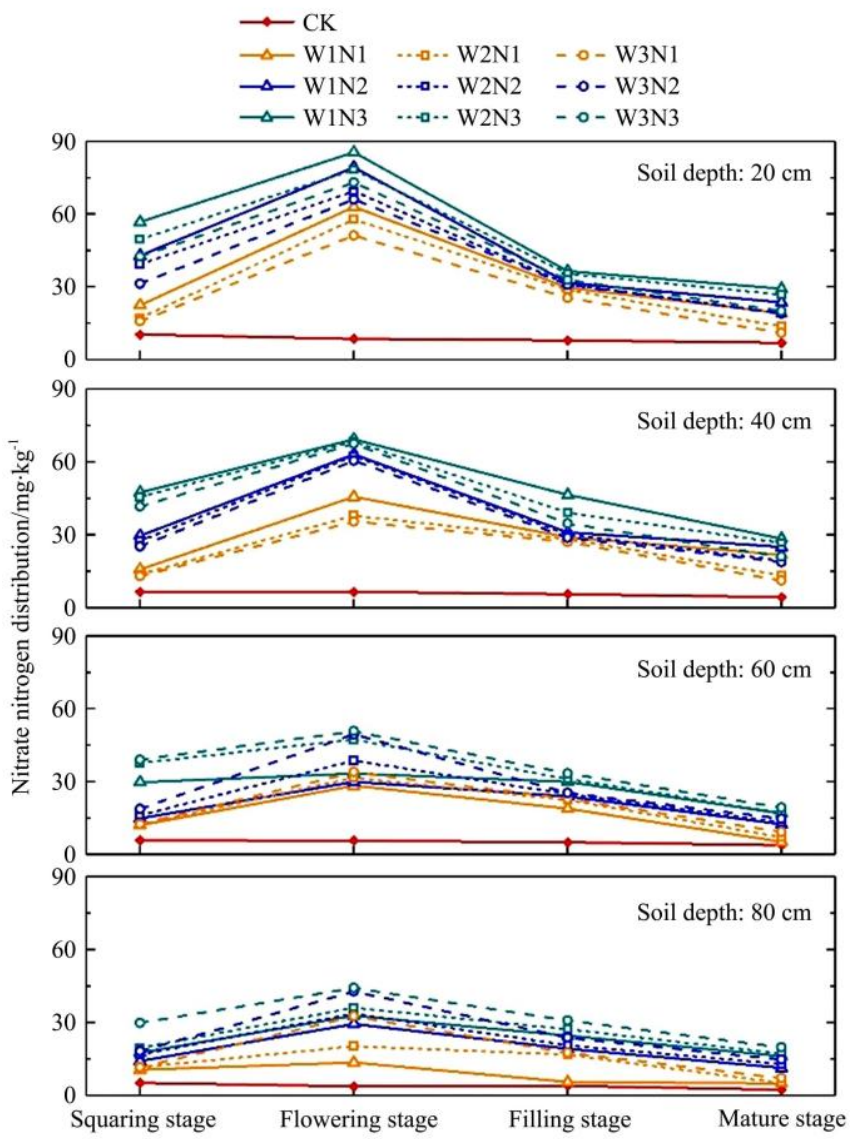

Figure 3 Nitrate nitrogen distribution in $0-80 \mathrm{~cm}$ soil profiles

3.1.2 Accumulation of soil nitrate-nitrogen

The tillage layer in the experimental location was $0-40 \mathrm{~cm}$ and was also the primary reservoir for nutrition absorption by crop roots. At different levels of irrigation and nitrogen fertilization, soil nitrate-nitrogen accumulation at 0-40 $\mathrm{cm}$ and $40-80 \mathrm{~cm}$ (Figure 4) increased at first and then decreased as the crops grew. Soil nitrate-nitrogen accumulation peaked during the flowering stage, reaching maximum values of $474.38 \mathrm{~kg} / \mathrm{hm}^{2}$ at $0-40 \mathrm{~cm}$ and $290.62 \mathrm{~kg} / \mathrm{hm}^{2}$ below the tillage layer at $40-80 \mathrm{~cm}$. Nitrate-nitrogen declined in subsequent growth phases, dropping to minimum values of $67.78 \mathrm{~kg} / \mathrm{hm}^{2}$ at $0-40 \mathrm{~cm}$ and $31.12 \mathrm{~kg} / \mathrm{hm}^{2}$ at $40-80 \mathrm{~cm}$ during the mature stage. Throughout growth, the 
accumulation of nitrate-nitrogen was improved by larger nitrogen application rates under a given irrigation condition. With nitrogen application being held constant, increased irrigation was associated with less soil nitrate-nitrogen accumulation. With increased water and nitrogen application, the relative accumulation of nitrate-nitrogen in $40-80 \mathrm{~cm}$ soil increased, but the relative accumulation of nitrate-nitrogen in $0-40 \mathrm{~cm}$ soil decreased.

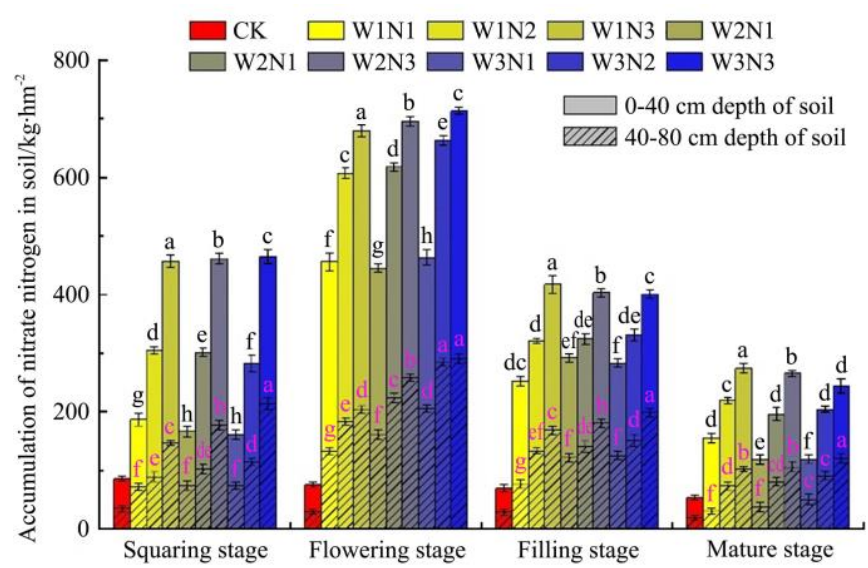

Note: The data is a bar stacked chart of $0-80 \mathrm{~cm}$, the error bars represent Standard Deviation (STD), and the significant difference groups of the mean values $(n=3)$ are indicated by lowercase letters $(p<0.05)$ for each soil layer.

Figure 4 Effects of different irrigation and nitrogen levels on nitrate-nitrogen accumulation in soil profiles

3.2 Effects of irrigation and $\mathrm{N}$ level on photosynthesis, transpiration, and $\mathrm{WUE}_{\mathrm{ins}}$ of sunflower

During the seedling stage, the net photosynthetic rates $(P n)$ of the top functional leaves were relatively small, with an average value of $26.16 \mu \mathrm{mol} / \mathrm{m}^{2} \cdot \mathrm{s}$ across the different treatments (Table 3), but they then peaked during the squaring stage, reaching an average value of $43.68 \mu \mathrm{mol} / \mathrm{m}^{2} \cdot \mathrm{s}$ across the different treatments. Then, $P n$ decreased rapidly during the flowering and filling stages, reaching their lowest values at the end of the filling stage, with an average of $23.99 \mu \mathrm{mol} / \mathrm{m}^{2} \cdot \mathrm{s}$. The average value of $P n$ reduced by $34.32 \%$ over the growth period from squaring to flowering and by $16.38 \%$ from flowering to filling. The patterns in the transpiration rate $(\mathrm{Tr})$ were similar to $P n$ across the different treatments throughout the sunflower growing season. Over the whole growth period, at the end of the seedling stage, the average $T r$ value was relatively small $\left(5.01 \mu \mathrm{mol} / \mathrm{m}^{2} \cdot \mathrm{s}\right)$, but it reached its highest at the end of the squaring stage $\left(5.24 \mu \mathrm{mol} / \mathrm{m}^{2} \cdot \mathrm{s}\right)$. Then, $\operatorname{Tr}$ rates declined rapidly at the end of the filling stage, registering average values of just $3.34 \mu \mathrm{mol} / \mathrm{m}^{2} \cdot \mathrm{s}$. The results of ANOVA showed that the coupling effect of water and nitrogen on photosynthesis was highly significant throughout sunflower growth, but only had a significant effect on transpiration during the filling stage.

Under the same irrigation water amount, the maximum $P n$ often appeared at the N2 level, and a low or high fertilization level reduced $P n$. Similarly, under the same fertilization level, the maximum of $P n$ often appeared in the W2 irrigation level. $P n$ of W2N2 was basically at a high level in the whole growth period, even being significantly higher than other treatments in the flowering period. $\mathrm{WUE}_{\text {ins }}$ at different levels of water and nitrogen supply increased first, then decreased, and then rebounded slightly. In the squaring stage, all treatments reached the maximum value of $\mathrm{WUE}_{\text {ins }}$ except W3N1.With a value in the W2N2 treatment of 8.00 $\mathrm{mol} / \mathrm{mmol}$, which was $15.3 \%$ lower than the highest treatment (W3N3) during this stage, the value of $\mathrm{WUE}_{\text {ins }}$ in the W2N2 treatment was at a medium level among the different treatments for the entire growth period.

Table 3 Effects of different irrigation and nitrogen levels on leaf net photosynthesis rate $(P n)$, transpiration rate $(T r)$, and WUE $E_{\text {ins }}$

\begin{tabular}{|c|c|c|c|c|c|c|c|c|c|c|c|c|}
\hline \multirow[b]{2}{*}{ Treatments } & \multicolumn{3}{|c|}{ Seedling stage } & \multicolumn{3}{|c|}{ Squaring stage } & \multicolumn{3}{|c|}{ Flowering stage } & \multicolumn{3}{|c|}{ Filling stage } \\
\hline & $\begin{array}{c}P n \\
/ \mu \mathrm{mol} \cdot \mathrm{m}^{-2} \cdot \mathrm{s}^{-1}\end{array}$ & $\begin{array}{c}\operatorname{Tr} \\
/ \mu \mathrm{mol} \cdot \mathrm{m}^{-2} \cdot \mathrm{s}^{-1}\end{array}$ & $\mathrm{WUE}_{\mathrm{ins}}$ & $\begin{array}{c}P n \\
/ \mu \mathrm{mol} \cdot \mathrm{m}^{-2} \cdot \mathrm{s}^{-1}\end{array}$ & $\begin{array}{c}\operatorname{Tr} \\
/ \mu \mathrm{mol} \cdot \mathrm{m}^{-2} \cdot \mathrm{s}^{-1}\end{array}$ & $\mathrm{WUE}_{\text {ins }}$ & $\begin{array}{c}P n \\
/ \mu \mathrm{mol} \cdot \mathrm{m}^{-2} \cdot \mathrm{s}^{-1}\end{array}$ & $\begin{array}{c}T r \\
/ \mu \mathrm{mol} \cdot \mathrm{m}^{-2} \cdot \mathrm{s}^{-1}\end{array}$ & $\mathrm{WUE}_{\mathrm{ins}}$ & $\begin{array}{c}P n \\
/ \mu \mathrm{mol} \cdot \mathrm{m}^{-2} \cdot \mathrm{s}^{-1}\end{array}$ & $\begin{array}{c}\operatorname{Tr} \\
/ \mu \mathrm{mol} \cdot \mathrm{m}^{-2} \cdot \mathrm{s}^{-1}\end{array}$ & WUE $_{\text {ins }}$ \\
\hline $\mathrm{CK}$ & 19.36 & 3.91 & 4.95 & 35.26 & 4.51 & 7.82 & 23.26 & 4.33 & 5.37 & 16.25 & 2.11 & 7.70 \\
\hline W1N1 & $26.12^{\mathrm{ab}}$ & $4.60^{\mathrm{bc}}$ & $5.68^{\mathrm{a}}$ & $42.99^{\mathrm{abc}}$ & $5.09^{\mathrm{ab}}$ & $8.49^{\mathrm{ab}}$ & $27.81^{\text {def }}$ & 4.41 & 6.53 & $19.41^{\mathrm{e}}$ & $3.31^{\mathrm{ab}}$ & $5.90^{\mathrm{c}}$ \\
\hline $\mathrm{W} 1 \mathrm{~N} 2$ & $27.62^{\mathrm{abc}}$ & $5.33^{\mathrm{a}}$ & $5.18^{\mathrm{ab}}$ & $43.63^{\mathrm{ab}}$ & $5.30^{\mathrm{ab}}$ & $8.24^{\mathrm{ab}}$ & $28.32^{\text {cde }}$ & 4.75 & 5.93 & $24.41^{\mathrm{bc}}$ & $3.42^{\mathrm{ab}}$ & $7.48^{\mathrm{bc}}$ \\
\hline $\mathrm{W} 1 \mathrm{~N} 3$ & $22.64^{\mathrm{d}}$ & $5.03^{\mathrm{abc}}$ & $4.51^{\mathrm{b}}$ & $41.20^{\mathrm{bc}}$ & $5.21^{\mathrm{ab}}$ & $7.95^{\mathrm{b}}$ & $27.41^{\mathrm{f}}$ & 4.40 & 6.23 & $21.70^{\mathrm{d}}$ & $3.20^{\mathrm{ab}}$ & $6.85^{\mathrm{bc}}$ \\
\hline W2N1 & $27.30^{\mathrm{ab}}$ & $5.17^{\mathrm{abc}}$ & $5.29^{\mathrm{ab}}$ & $44.31^{\mathrm{a}}$ & $5.24^{\mathrm{ab}}$ & $8.59^{\mathrm{ab}}$ & $27.10^{\mathrm{f}}$ & 5.10 & 5.34 & $24.02^{\mathrm{bc}}$ & $3.30^{\mathrm{ab}}$ & $7.30^{\mathrm{bc}}$ \\
\hline $\mathrm{W} 2 \mathrm{~N} 2$ & $28.03^{\mathrm{a}}$ & $5.33^{\mathrm{a}}$ & $5.26^{\mathrm{ab}}$ & $45.55^{\mathrm{a}}$ & $5.71^{\mathrm{a}}$ & $8.00^{\mathrm{b}}$ & $32.00^{\mathrm{a}}$ & 5.46 & 6.28 & $26.85^{\mathrm{a}}$ & $3.80^{\mathrm{a}}$ & $7.08^{\mathrm{bc}}$ \\
\hline $\mathrm{W} 2 \mathrm{~N} 3$ & $27.70^{\mathrm{ab}}$ & $5.07^{\mathrm{abc}}$ & $5.46^{\mathrm{a}}$ & $44.11^{\mathrm{a}}$ & $5.41^{\mathrm{ab}}$ & $8.21^{\mathrm{ab}}$ & $27.61^{\mathrm{ef}}$ & 5.33 & 5.32 & $25.11^{\mathrm{ab}}$ & $3.81^{\mathrm{a}}$ & $6.60^{\mathrm{bc}}$ \\
\hline W3N1 & $23.75^{\mathrm{cd}}$ & $4.90^{\mathrm{abc}}$ & $4.86^{\mathrm{ab}}$ & $40.91^{\mathrm{c}}$ & $5.04^{\mathrm{ab}}$ & $8.20^{\mathrm{ab}}$ & $30.53^{\mathrm{b}}$ & 4.61 & 6.64 & $25.62^{\mathrm{ab}}$ & $2.82^{\mathrm{b}}$ & $9.17^{\mathrm{a}}$ \\
\hline W3N2 & $26.94^{\mathrm{ab}}$ & $5.20^{\mathrm{ab}}$ & $5.30^{\mathrm{ab}}$ & $45.14^{\mathrm{a}}$ & $5.36^{\mathrm{ab}}$ & $8.38^{\mathrm{ab}}$ & $28.91^{\mathrm{c}}$ & 5.21 & 5.60 & $26.03^{\mathrm{ab}}$ & $3.62^{\mathrm{a}}$ & $7.23^{\mathrm{bc}}$ \\
\hline W3N3 & $25.33^{\mathrm{bc}}$ & $4.50^{\mathrm{c}}$ & $5.64^{\mathrm{a}}$ & $45.30^{\mathrm{a}}$ & $4.81^{\mathrm{b}}$ & $9.45^{\mathrm{a}}$ & $28.61^{\mathrm{cd}}$ & 4.52 & 6.36 & $22.80^{\mathrm{cd}}$ & $2.82^{\mathrm{b}}$ & $8.14^{\mathrm{ab}}$ \\
\hline Average & 26.16 & 5.01 & 5.24 & 43.68 & 5.24 & 8.39 & 28.7 & 4.87 & 6.03 & 23.99 & 3.34 & 7.31 \\
\hline \multicolumn{13}{|c|}{$P$ values } \\
\hline $\mathrm{W}$ & $<0.05$ & 0.252 & 0.700 & 0.089 & 0.138 & 0.346 & 0.118 & 0.075 & 0.401 & $<0.01$ & $<0.05$ & $<0.01$ \\
\hline $\mathrm{N}$ & $<0.05$ & $<0.05$ & 0.963 & 0.090 & 0.090 & 0.629 & $<0.05$ & 0.343 & 0.875 & $<0.05$ & 0.079 & 0.890 \\
\hline $\mathrm{W}^{*} \mathrm{~N}$ & $<0.01$ & 0.086 & 0.113 & $<0.01$ & 0.231 & 0.299 & $<0.01$ & 0.512 & 0.710 & $<0.01$ & $<0.05$ & $<0.01$ \\
\hline
\end{tabular}

Note: The significant difference groups of the mean values $(n=3)$ are denoted with lowercase letters $(p<0.05)$.

3.3 Interaction effects of irrigation and $\mathrm{N}$ levels on nutrient accumulation of sunflower

\subsubsection{Total-N content by organ}

The total nitrogen contents in different organs (leaves, stem, and flower disk) of sunflower are provided in Figure 5. The accumulation of total nitrogen in sunflower plants increased throughout the growth period, and reached the maximum at the mature stage. We also observed that when the irrigation amount was at W1 and W2, the total nitrogen of each treatment increased first and then decreased with the increase in nitrogen application. When the irrigation amount was at W3 during the squaring and flowering stage, the total nitrogen of each treatment increased with the increase in nitrogen application. Nonetheless, this relationship did not reach a significant level at the filling and mature stage. Overall, the total nitrogen accumulation in plants with the W2N2 treatment was the highest in all growth periods, i.e., 0.88, 2.29, 2.72 , and $2.84 \mathrm{~g} /$ plant, respectively.

The accumulation of total nitrogen in sunflower leaves 
increased initially and reached the maximum value at the flowering stage, accounting for $58.39 \%-70.72 \%$ of the total nitrogen content in the aboveground part of the plant. Then, the total nitrogen content began to decline. During the maturity stage, the nitrogen accumulation in leaves decreased to the lowest level of only $0.07-0.16 \mathrm{~g} /$ plant. The accumulation of nitrogen in the stem was small, reaching the maximum value in the flowering period, accounting for $4.06 \%-26.24 \%$ of the total nitrogen content in the

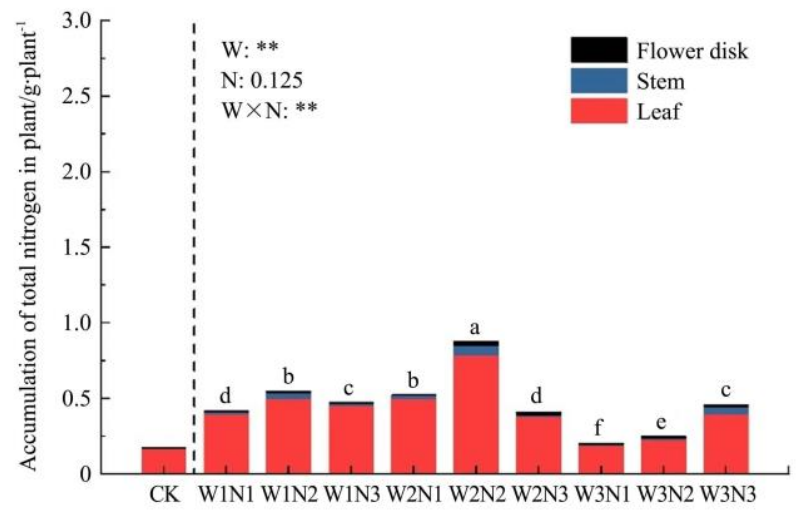
a. Squaring stage

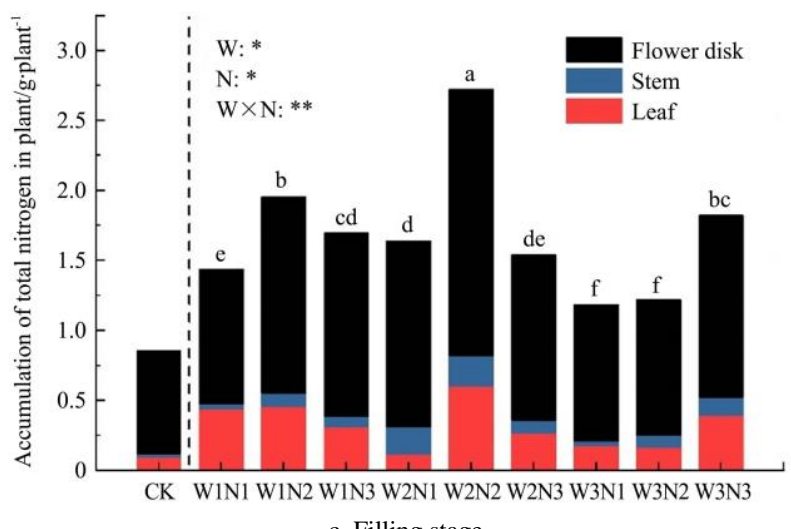
c. Filling stage aboveground part of the plant. Although the sunflower stems contained significantly less total nitrogen than the leaves, the general trend was basically the same, that is, it increased first, and then began to decline after flowering stage. The nitrogen accumulation in the flower disk was always on the rise. At maturity, the total nitrogen accumulation in the flower disks accounted for $89.07 \%-94.57 \%$ of the total nitrogen accumulation in the aboveground part of the plant.

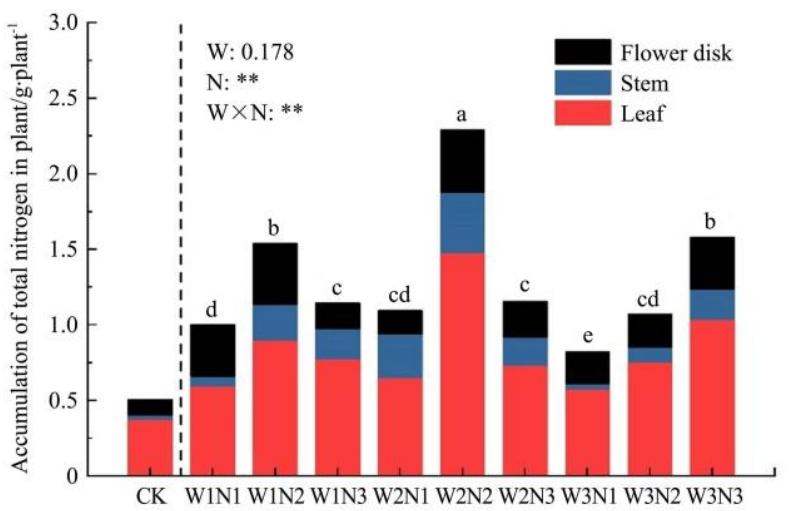

b. Flowering stage

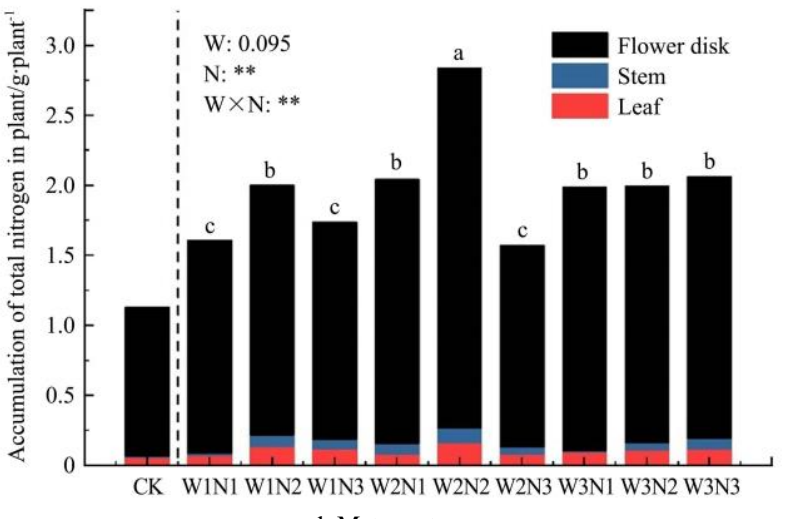

d. Mature stage

Note: Significant difference group for the mean values $(\mathrm{n}=3)$ is indicated by lowercase letters $(p<0.05)$. The $p$ values of the ANOVA tests for water regimes $(\mathrm{W})$, nitrogen treatments $(\mathrm{N})$, and their interactions $(\mathrm{W} \times \mathrm{N})$ are indicated: * denotes $p<0.05$ and $* *$ denotes $p<0.01$.

Figure 5 Nitrogen accumulation in leaves, stems, and flower disks at different growth stages

\subsubsection{Nitrogen transport, uptake, and utilization in plants}

At mature stage, the nitrogen transportation quantity and rate in the leaves and stem, and the amount of total nitrogen in the disk are presented in Table 4. The transportation quantity of leaves was $0.48-1.32 \mathrm{~g} / \mathrm{plant}$, with transportation rates ranging from $82.97 \%$ to $89.16 \%$. The transportation quantity and rates were considerably smaller in the stems at $0.02-0.29 \mathrm{~g} / \mathrm{plant}$ and $50.68 \%$ $73.85 \%$, respectively. The interaction effects of irrigation and nitrogen fertilizer on total nitrogen transportation quantity and rate, total nitrogen yield, and the yield of leaves and stems were significant $(p<0.05)$. Moreover, nitrogen had a significant effect on the nitrogen transport of leaves, while the nitrogen transport of stems was mainly affected by the irrigation amount. Under the W2N2 treatment, the transport quantity of leaf and stem reached the maximum, which also led to a significantly higher disk nitrogen accumulation quantity of W2N2 than other treatments. The effect of water-nitrogen coupling on the accumulation of nitrogen in flower disk was highly significant.

\subsection{Sunflower yield components}

Figure 6 shows the yield components of sunflower. The interaction of water and fertilizer reached a highly significant level at the setting percentage, seed weight per flower disk, thousand-grain weight, yields, $i W U E$ and $N_{P F P}$. We conducted ANOVA on the data of two years. The $p$ values of setting percentage, seed weight per flower disk, thousand-grain weight, and yield were $0.69,0.444$, 0.116 , and 0.566 , respectively. Therefore, the planting years had no significant effect on the yield components of sunflower. However, the effect of water or nitrogen single factor on yield components was not the same in two years, which may be affected by climate factors. W2N2 had the highest setting percentage and seed weight per flower disk, which was significantly higher than the other treatments, reaching $96.97 \%$ and $112.96 \mathrm{~g}$ on average. The yield of W2N2 (3 $597 \mathrm{~kg} / \mathrm{hm}^{2}$ ) was also higher than that of the other treatments; in terms of sunflower yield, the optimal water-nitrogen combination was W2N2, but the $i W U E$ and $N_{P F P}$ of W2N2 were not the highest. The $i W U E$ was highest in W1N2 $\left(1.61 \mathrm{~kg} / \mathrm{m}^{3}\right), N_{P F P}$ was highest in W2N1 $(18.93 \mathrm{~kg} / \mathrm{kg})$.

In order to determine a reasonable irrigation strategy, taking irrigation and fertilization amount as independent variables, and setting percentage, seed weight per flower disk, thousand-grain weight, yield, $i W U E$, and $N_{P F P}$ as dependent variables, six regression equations were established (Table 5). After data normalization, the contour lines of the maximum value of each factor in different intervals are extracted. When the yield reaches the maximum value (Figure 7a), setting percentage, seed weight per flower disk, and thousand-grain weight can also be in 
the range of $95 \%$ of the maximum. In the case of only considering the yield components, it is concluded that the irrigation amount of $272.45 \mathrm{~mm}$ and the fertilization application of $233.43 \mathrm{~kg} / \mathrm{hm}^{2}$ is a good irrigation strategy, thus ensuring that the yield of sunflower can reach $3426.7 \mathrm{~kg} / \mathrm{hm}^{2}$. When $i W U E$ and $N_{P F P}$ were considered, the intersection occurs at $75 \%$ level of each index (Figure 7b), the irrigation water in the range of 241.62-253.35 mm and the amount of fertilizer in the range of $202.02-209.40 \mathrm{~kg} / \mathrm{hm}^{2}$ is a reasonable irrigation strategy, the yield of sunflower can reach $3229.3 \mathrm{~kg} / \mathrm{hm}^{2}$.

Table 4 Effects of different irrigation and nitrogen levels on nitrogen transportation in leaves and stems, and nitrogen increment in flower disks

\begin{tabular}{|c|c|c|c|c|c|}
\hline \multirow{2}{*}{ Treatments } & \multicolumn{2}{|c|}{ Leaf translocation } & \multicolumn{2}{|c|}{ Steam translocation } & \multirow{2}{*}{$\begin{array}{l}\text { Disk translocation } \\
\text { quantity/g. } \text { plant }^{-1}\end{array}$} \\
\hline & Quantity/g. plant ${ }^{-1}$ & Rate/\% & Quantity/g.plant ${ }^{-1}$ & Rate/\% & \\
\hline $\mathrm{CK}$ & 0.33 & 78.26 & 0.004 & 45.36 & 0.93 \\
\hline $\mathrm{W} 1 \mathrm{~N} 1$ & $0.53^{\mathrm{f}}$ & $88.28^{\mathrm{ab}}$ & $0.05^{\mathrm{e}}$ & $72.64^{\mathrm{ab}}$ & $1.18^{\mathrm{f}}$ \\
\hline W1N2 & $0.76^{\mathrm{c}}$ & $84.77^{\mathrm{abc}}$ & $0.16^{\mathrm{c}}$ & $65.42^{\mathrm{bc}}$ & $1.38^{\mathrm{e}}$ \\
\hline W1N3 & $0.66^{\mathrm{d}}$ & $84.47^{\text {bc }}$ & $0.13^{\mathrm{d}}$ & $65.67^{\mathrm{abc}}$ & $1.37^{\mathrm{e}}$ \\
\hline W2N1 & $0.57^{\mathrm{e}}$ & $87.80^{\mathrm{ab}}$ & $0.21^{\mathrm{b}}$ & $72.50^{\mathrm{ab}}$ & $1.73^{\mathrm{b}}$ \\
\hline W2N3 & $0.65^{\mathrm{d}}$ & $89.06^{\mathrm{ab}}$ & $0.14^{\text {cd }}$ & $72.72^{\mathrm{ab}}$ & $1.20^{\mathrm{f}}$ \\
\hline W3N1 & $0.48^{\mathrm{g}}$ & $82.97^{\mathrm{c}}$ & $0.02^{\mathrm{f}}$ & $70.70^{\mathrm{ab}}$ & $1.67^{\mathrm{bc}}$ \\
\hline W3N2 & $0.64^{\mathrm{d}}$ & $84.91^{\mathrm{abc}}$ & $0.05^{\mathrm{e}}$ & $50.68^{\mathrm{d}}$ & $1.61^{\mathrm{cd}}$ \\
\hline W3N3 & $0.92^{\mathrm{b}}$ & $88.78^{\mathrm{ab}}$ & $0.12^{\mathrm{d}}$ & $61.33^{\mathrm{c}}$ & $1.53^{\mathrm{d}}$ \\
\hline \multicolumn{6}{|c|}{$P$ values } \\
\hline $\mathrm{W}$ & 0.191 & $<0.05$ & $<0.01$ & $<0.01$ & $<0.01$ \\
\hline $\mathrm{W}^{*} \mathrm{~N}$ & $<0.01$ & $<0.05$ & $<0.01$ & $<0.01$ & $<0.01$ \\
\hline
\end{tabular}

Note: The significant difference groups of the mean values $(n=3)$ are denoted with lowercase letters $(p<0.05)$. The $p$ values of the ANOVA tests for water regimes (W), nitrogen treatments $(\mathrm{N})$, and their interactions $(\mathrm{W} \times \mathrm{N})$ are indicated.
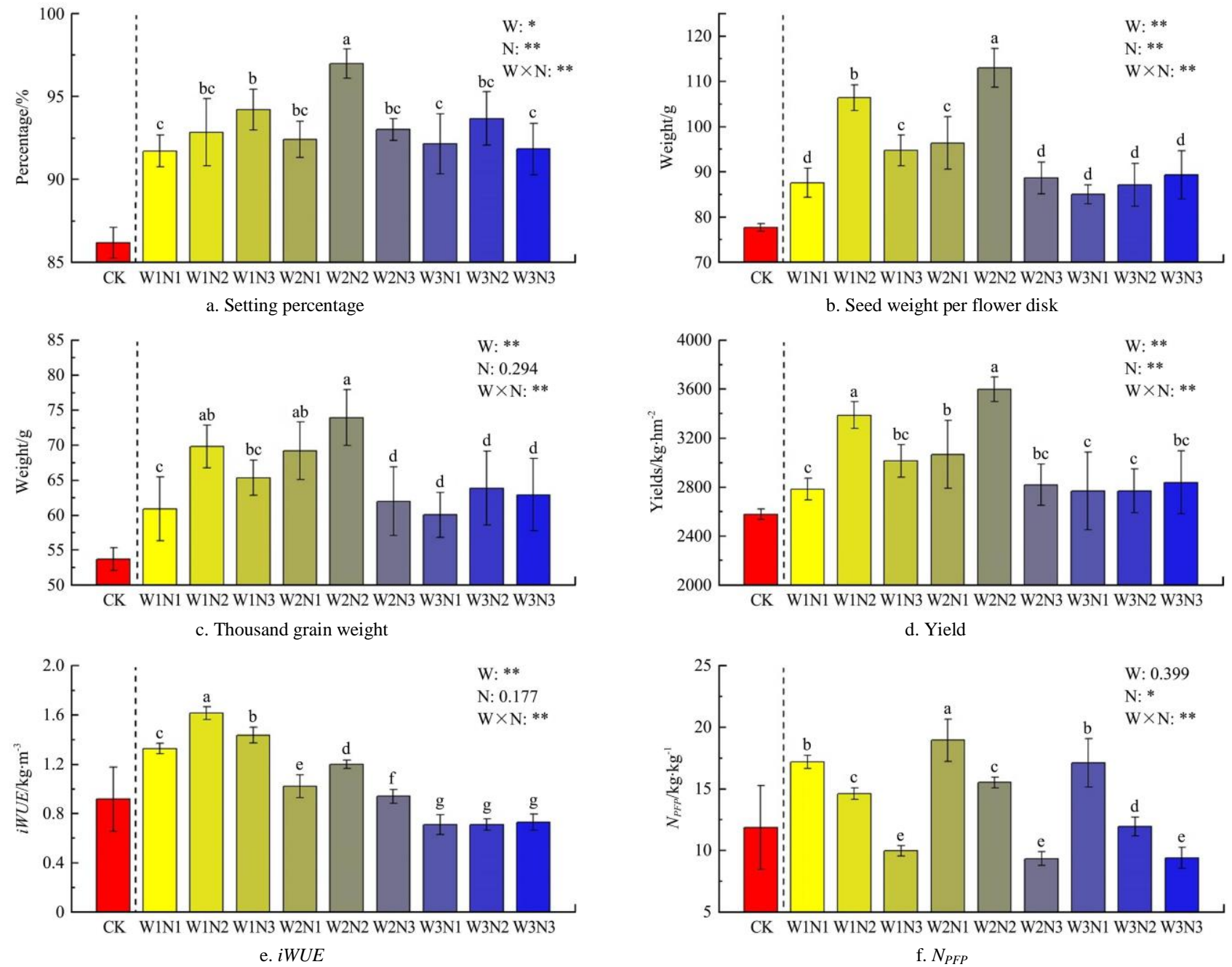

Note: The significant difference group of the mean values $(n=3)$ is shown by lowercase letters $(p<0.05)$, the error bars represent STD. The $p$ values of the ANOVA tests for water regimes $(\mathrm{W}), \mathrm{N}$ treatments $(\mathrm{N})$, and their interactions $(\mathrm{W} \times \mathrm{N})$ are indicated: * denotes $p<0.05$ and $* *$ denotes $p<0.01$.

Figure 6 Effects of different irrigation and nitrogen levels on (a) setting percentage, (b) seed weight per flower disk, (c) thousand-grain weight, (d) sunflower yield, (e) $i W U E$, and (f) $N_{P F P}$ 
Table 5 Regression equations between irrigation amount and nitrogen application rate and setting percentage, seed weight per flower disk thousand-grain weight, and yields

\begin{tabular}{|c|c|c|c|}
\hline Response variable $Y$ & Regression equation & $R^{2}$ & $P$ Value \\
\hline Setting percentage & $Y=50.05958+0.1264 W+0.22333 N-1.71605 * 10^{-4} W^{2}-3.95918 * 10^{-4} N^{2}-1.09524 * 10^{-4} W N$ & 0.69 & $<0.01$ \\
\hline Seed weight per flower disk & $Y=-103.42471+0.5428 W+1.17022 N-9.43747 * 10^{-4} W^{2}-2.43 * 10^{-3} N^{2}-1.15789 * 10^{-4} W N$ & 0.71 & $<0.01$ \\
\hline Thousand-grain weight & $Y=-41.16747+0.3343 W+0.56699 N-5.61728 * 10^{-4} W^{2}-0.00118 N^{2}-6.19048 * 10^{-5} W N$ & 0.70 & $<0.01$ \\
\hline Yields & $Y=-3279.29103+17.3495 W+37.0183 N-2.89564 * 10^{-2} W^{2}-0.07542 N^{2}-6.34011 * 10^{-3} W N$ & 0.69 & $<0.01$ \\
\hline$i W U E$ & $Y=0.86079-5.72914 * 10^{-3} W+0.01514 N+4.08356 * 10^{-6} W^{2}-3.00533 * 10^{-5} N^{2}-3.62802 * 10^{-6} W N$ & 0.97 & $<0.01$ \\
\hline
\end{tabular}

Note: $W$ is irrigation amount, $\mathrm{mm} ; N$ is nitrogen application, $\mathrm{kg} / \mathrm{hm}^{2}$.
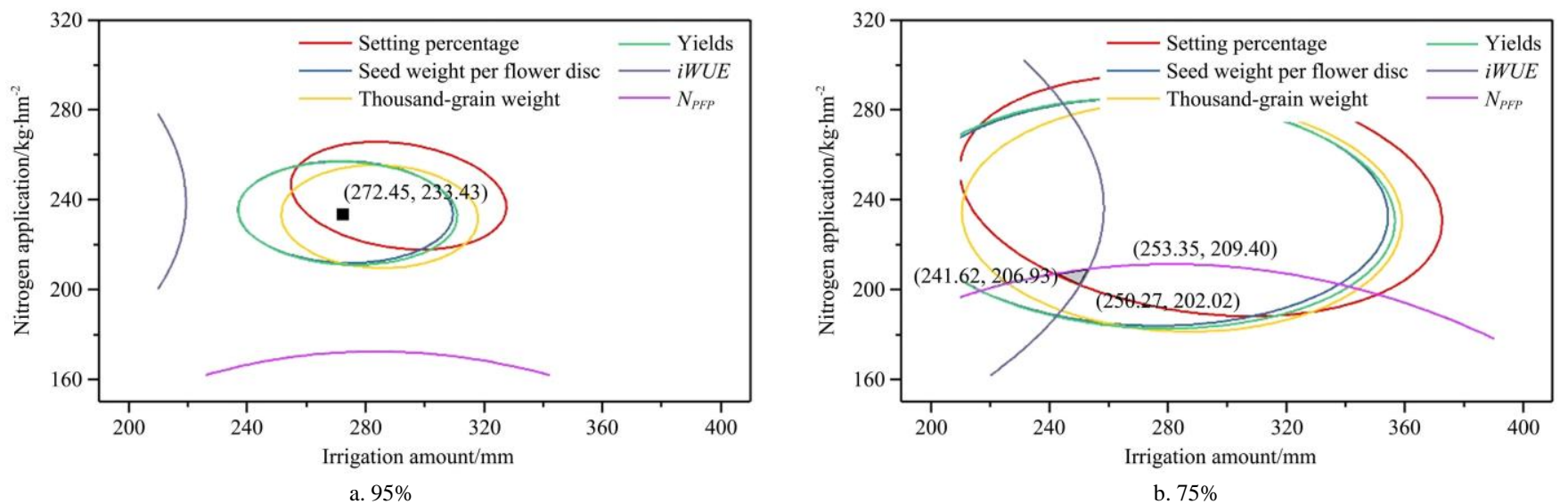

Note: After data normalization, the grid area in the (a) and (b) is a reasonable acceptable range for each response indicator to be greater than the 0.95 and 0.75 levels, respectively.

Figure 7 Comprehensive analysis of optimal irrigation strategy based on yield components and water and nitrogen use efficiency

\section{Discussion}

Sunflower roots mainly absorb nutrients in the tillage soil layer $(0-40 \mathrm{~cm})$. The nitrogen accumulation in tillage and deeper layers (40-80 cm soil depth) first increased, reached the maximum in the flowering stage, and then decreased with the sunflower growth. The quantity of soil nitrate-nitrogen in the shallow soil decreased noticeably, but it remained higher in the deeper soil because the formation of sunflower seeds required large amounts of soil nitrogen in the shallow soil. Some studies showed that the reduction of nitrate accumulation in the tillage soil layer under heavy irrigation was related not only to the crop's consumption of nitrate but also to leaching triggered by the irrigation ${ }^{[35]}$.

The common drip irrigation system in Xinjiang usually needs a fertilizer equipment (also called pressure tank) to apply water-soluble fertilizer, which leads to a gradual decrease of fertilizer concentration in water with the increase of irrigation amount and irrigation time ${ }^{[36,37]}$. Under this condition, the interaction of irrigation and fertilization will affect the accumulation of nitrate-nitrogen in the soil. In this study, a small irrigation amount $(210 \mathrm{~mm})$ causes the increased accumulation of nitrate-nitrogen in the surface soil $(0-40 \mathrm{~cm})$ because it has less leaching effect; this finding was also obtained by Zhang et al. ${ }^{[38]}$ However, if the nitrate-nitrogen content in the soil is higher, does it mean that crops will grow better? The result indicates otherwise. Moraes et al. ${ }^{[39]}$ showed that the application amount of nitrogen fertilizer had a significant effect on the physiological growth of sunflower. But this does not mean that blindly increasing the application of nitrogen fertilizer will promote sunflower growth.

In general, the photosynthesis of sunflower reaches the maximum at squaring stage (or so-called heading stage), and then decreases with the plant age ${ }^{[40]}$. In arid areas, the effect of irrigation and fertilization on crop's photosynthesis is very obvious ${ }^{[41-44]}$. The increase in irrigation and fertilization will promote the photosynthesis and transpiration of crops ${ }^{[45,46]}$. However, once a threshold value is exceeded, excessive fertilization and irrigation will inhibit the photosynthetic characteristics of crops ${ }^{[47]}$. In this study, when the irrigation level reaches W3, the nitrate-nitrogen content in the soil under W3 level was the lowest under the same fertilization level (N1, N2, N3). The excessive irrigation amount may have an obvious leaching effect on soil nitrogen, which also weakens the promotion of fertilization in the photosynthetic characteristics of sunflowers. On the other hand, it is not feasible to apply large amounts of fertilizer to promote photosynthesis, because a high soil nitrate-nitrogen content will lead to potential toxicity ${ }^{[48]}$. The growth of many crops under a high concentration of nitrate has been inhibited, and the decline of photosynthesis is one of the main manifestations ${ }^{[49-51]}$. In our case, the sunflower growth appeared a similar phenomenon. This phenomenon was most obvious during the flowering stage when the average soil nitrate-nitrogen reached $51.1 \mathrm{mg} / \mathrm{kg}$.

Pascual et al. ${ }^{[52]}$ showed that $\mathrm{WUE}_{\text {ins }}$ is determined by plant water status and nitrogen application, which could reflect the response of plants to the coupling of water and fertilizer to a certain extent. In our experiment, the $\mathrm{WUE}_{\text {ins }}$ of each treatment did not show an obvious change rule, but overall, $\mathrm{WUE}_{\text {ins }}$ increased with the increase in irrigation amount, especially at the squaring and filling stages. Meanwhile, fertilization had a minimal effect on $\mathrm{WUE}_{\text {ins. }}$. Guizani et al. ${ }^{[53]}$ found that irrigation deficit can improve the WUE $E_{\text {ins }}$ of crops. The reason for this result is that irrigation deficit will reduce the $P n$ and $T r$ of crops, but their ratio will increase, as reflected in the increase of $\mathrm{WUE}_{\text {ins. }}$. In our experiment, under the condition of fertilization, the $P n$ and $T r$ of sunflowers will increase, and the $\mathrm{WUE}_{\text {ins }}$ will also increase with the increase in the irrigation amount, thereby indicating that sunflower grows with improved efficiency of water and fertilizer utilization. 
Soil nutrients are absorbed, accumulated, transported, and distributed to support the reproductive crop organs, which are typically the basis of crop yield ${ }^{[54]}$. It is feasible to adjust the nitrogen absorption of crops by changing the amount of water and fertilizer ${ }^{[55,56]}$. As for sunflower, in the reproductive growth stage (late growth period), nitrogen was mainly accumulated in the flower disk, as it was transferred from leaves and stems to seeds and promoted the formation of yield ${ }^{[57]}$. At low or moderate levels of nitrogen fertilization, a certain range of irrigation increase (below $300 \mathrm{~mm}$ ) could accelerate nitrogen accumulation and transportation in leaves and stems, thus significantly increasing the yield of sunflower. With low or moderate irrigation levels, an increase in nitrogen application (below $232 \mathrm{~kg} / \mathrm{hm}^{2}$ ) would improve nitrogen accumulation in organs and boost the amount of transportation from leaves and stems to flower disks, leading to a higher yield of sunflower. This result is similar to the findings of Wang et al. ${ }^{[58]}$

In addition, The nitrogen required for seed formation of sunflower mainly depends on the accumulated nitrogen absorbed by crops before flowering, which is supported by nitrogen redistribution in vegetative tissues ${ }^{[59]}$. Seeds began to form at the later stage of reproductive development, and the transfer of nitrogen to seed was related to seed growth. Compared with stem, leaf is the main source of nitrogen for seeds ${ }^{[60]}$. The accumulation of total nitrogen in leaves sharply declined after flowering, just as total nitrogen began accumulating rapidly in the flower disks. The moderate rate (W2N2: $300 \mathrm{~mm} \& 232 \mathrm{~kg} / \mathrm{hm}^{2}$ ) of water and nitrogen supply used in this study was the most beneficial for flower disk nitrogen accumulation. Through the redistribution of nitrogen, increasing the nitrogen content in the flower disk has a positive significance to improve the nitrogen use efficiency and yield of sunflower.

The crop yield is the most concerned point for farmers. If we take the increase of yield as the main evaluation basis, the theoretical maximum yield can be achieved when the irrigation amount is $272.45 \mathrm{~mm}$, and the fertilizer amount is $233.43 \mathrm{~kg} / \mathrm{hm}^{2}$. But in this case, $i W U E$ and $N_{P F P}$ will reduce, which means a waste of water resources and fertilizer. In arid areas like Xinjiang, water resources are very scarce ${ }^{[61]}$. Kiani et al. ${ }^{[62]}$ indicated that increasing the amount of nitrogen fertilizer was not a suitable strategy under severe deficit irrigation. With the $\mathrm{N}$ application from 0 to $93 \mathrm{~kg} / \mathrm{hm}^{2}$, the seed yield of two hybrids sunflower reduced $25 \%$ and $32 \%$, respectively. Therefore, it is necessary to consider irrigation strategy more comprehensively. Finally, in combination with yield components and irrigation water and fertilizer use efficiency, the results showed that the irrigation amount should be $241.62-253.35 \mathrm{~mm}$, and the fertilization rate should be $202.02-209.40 \mathrm{~kg} / \mathrm{hm}^{2}$, which is a reasonable irrigation strategy. Its yield is lower than the maximum theoretical yield, but it is still within the acceptable range. In fact, there are some differences in the amount of irrigation and nitrogen applied for sunflower in different areas. Wan et al. ${ }^{[63]}$ planted sunflower on alkaline soil and found that the irrigation efficiency was the highest when the irrigation amount reached $750 \mathrm{~mm}$. Rafiei et al. ${ }^{[64]}$ indicated that the application of $150 \mathrm{~kg} / \mathrm{hm}^{2}$ could meet the demand for the growth of sunflower. Nasim and Bano ${ }^{[65]}$ believed that $240 \mathrm{~kg} / \mathrm{hm}^{2}$ was a reasonable amount of fertilizer, and the yield of sunflower could reach the maximum. The reason for this difference is the different irrigation methods and soil quality in the planting area. The soil fertility in Xinjiang is poor because the cultivated land mostly comes from wasteland reclamation ${ }^{[66]}$. At the same time, because of high evaporation, the irrigation and fertilizer amount in this area are generally higher. However, the application of drip irrigation system improves the efficiency of water and fertilizer utilization to a certain extent, the irrigation amount and fertilizer application amount in Xinjiang are still within a reasonable range. Other areas should adjust the amount of irrigation and fertilization according to the soil quality, climate conditions, irrigation technology, and other conditions.

\section{Conclusions}

Different coupling of water and fertilizer application will change the accumulation of nitrogen in soil, which will affect the growth of sunflower. The photosynthesis of sunflower was significantly affected by the coupling of water and nitrogen and reached the maximum at the squaring stage, while the transpiration was less affected by the water-nitrogen coupling. The accumulation of nitrogen was concentrated in the sunflower leaves during the early growth stage, whereas this focus shifted to the disk in the late growth stage. Under W2N2 (300 mm and $\left.232 \mathrm{~kg} / \mathrm{hm}^{2}\right)$, the nitrogen transfer from leaf and stem to flower disks was the largest, and the accumulation of nitrogen in the flower disk was the largest. Reasonable coupling of water and nitrogen will be beneficial to the transfer of nitrogen to the flower disk of sunflower and will increase yield. Through the fitting analysis of yield components and water and fertilizer utilization efficiency, including the setting percentage, seed weight per flower disk, thousand-grain weights, yield, $i W U E$ and $N_{P F P}$, it is concluded that the irrigation amount of 241.62-253.35 mm and the fertilization application of $202.02-209.40 \mathrm{~kg} / \mathrm{hm}^{2}$ is a good irrigation strategy, which ensures that the yield of sunflower can reach $3229.3 \mathrm{~kg} / \mathrm{hm}^{2}$. This irrigation strategy may provide some reference for drip irrigation of sunflower in some similar arid areas.

\section{Acknowledgements}

The authors acknowledge that this research was financially supported by Scientific and Technological Innovation Team Project of Xinjiang Production and Construction Corps (Grant No. 2019CB004).

\section{[References]}

[1] Akcay S, Dagdelen N. Water use efficiency, yield and yield components of second crop sunflower under deficit irrigation. Turkish Journal of Field Crops, 2016; 21: 190-199.

[2] Angadi S V, Entz M H. Water relations of standard height and dwarf sunflower cultivars. Crop Science, 2002; 94: 136-145.

[3] Sinha I, Buttar G S, Brar A S. Drip irrigation and fertigation improve economics, water and energy productivity of spring sunflower (Helianthus annuus L.) in Indian Punjab. Agricultural Water Management, 2017; 185: 124-134.

[4] Zeng W, Wu J, Munir P H, Xu C, Ma T, Huang J. Testing the APSIM sunflower model on saline soils of Inner Mongolia, China. Field Crops Research, 2016; 192: 45-54.

[5] Lei G Q, Zeng W Z, Zhu J X, Zha Y Y, Fang Y H, Song Y X, et al Quantification of leaf growth, height increase, and compensatory root water uptake of sunflower in heterogeneous saline soils. Agronomy Jounal, 2019; 111(3): 1010-1027.

[6] García-López J, Lorite I J, García-Ruiz R, Ordoñez R, Dominguez J. Yield response of sunflower to irrigation and fertilization under semi-arid conditions. Agricultural Water Management, 2016; 176: 151-162.

[7] Li S X, Wang Z H, Hu T T, Gao Y J, Stewart B A. Nitrogen in dryland soils of China and its management. Advances in Agronomy, 2009; 101: 123-181.

[8] Li J M, Li H P, Li A G, Song C M, Liu G H. Influence of drip irrigation under film and seepage irrigation under film methods on growth of oil sunflower. Molecular Plant Breeding, 2018; 12: 4119-4123.

[9] Martinez R D, Poot W A P, Nava S C, Martinez M T D S, Ortega M E M. 
Yield and agronomic efficiency of sunflower in response to nitrogen fertilizer application and sowing season. Revista Caatinga, 2018; 31(4): 871-881.

[10] Zhang Y H, Tian S C, Yang J G, Fan L Q, Wu X M. Effects of irrigation methods on soil water and salt migration and oil sunflower yield. Chinese Agricultural Science Bulletin, 2017; 33(18): 71-75. (in Chinese)

[11] Fabeiro C, Olalla F M D, de Juan J A. Yield and size of deficit irrigated potatoes. Agricultural Water Management, 2001; 48: 255-266.

[12] Ferreira T C, Goncalves D A. Crop-yield/water-use production functions of potatoes (Solanum tuberosum L.) grown under differential nitrogen and irrigation treatments in a hot, dry climate. Agricultural Water Management, 2007; 90: 45-55

[13] Wei T, Dong Z Y, Zhang C, Ali S, Chen X L, Han Q F, et al. Effects of rainwater harvesting planting combined with deficiency irrigation on soil water use efficiency and winter wheat (Triticum aestivum L.) yield in a semiarid area. Field Crops Research, 2018; 218: 231-242.

[14] Li Q H, Chen Y N, Shen Y J, Li X G, Xu J H. Spatial and temporal trends of climate change in Xinjiang, China. Journal of Geographical Sciences, 2011; 21(6): 1007-1018.

[15] Sahoo P, Brar A S, Sharma S. Effect of methods of irrigation and sulphur nutrition on seed yield, economic and bio-physical water productivity of two sunflower (Helianthus annuus L.) hybrids. Agricultural Water Management, 2018; 206: 158-164.

[16] Sandhu O S, Gupta R K, Thind H S, Jat M L, Sidhu H S, Yadvinder-Singh. Drip irrigation and nitrogen management for improving crop yields, nitrogen use efficiency and water productivity of maize-wheat system on permanent beds in north-west India. Agricultural Water Management, 2019; 219: 19-26

[17] Sezen S M, Tekin S, Konuskan D B. Effect of irrigation strategies on yield of drip irrigated sunflower oil and fatty acid composition and its economic returns. Journal of Agricultural Sciences-Tarim Bilimleri Dergisi, 2019; 25(2): 163-173.

[18] Elnaz E, Seyyed M S, Ahmad B, Christos A D. Seed yield and oil quality of sunflower, safflower, and sesame under different levels of irrigation water availability. Agricultural Water Management, 2019; 218: 149-157.

[19] Karam F, Lahoud R, Masaad R, Kabalan R, Breidi J, Chalita C, et al. Evapotranspiration, seed yield and water use efficiency of drip irrigated sunflower under full and deficit irrigation conditions. Agricultural Water Management, 2007; 90: 213-223.

[20] Nasim W, Belhouchette H, Tariq M. Correlation studies on nitrogen for sunflower crop across the agroclimatic variability. Environmental Science and Pollution Research, 2016; 23(4): 3658-3670.

[21] Gul V, Kara K. Effects of different nitrogen doses on yield and quality traits of common sunflower (Helianthus annuus L.). Turkish Journal of Field Crops, 2015; 20(2): 159-165.

[22] Kara K. The effects of doses applied at different growing periods on the quality and yield of oil type sunflower (Helianthus annuus L.) varieties. Turkish Journal of Field Crops, 2018; 23(2): 195-205.

[23] Eskandari A, Khazaie H R, Nezami A, Kafi M, Majdabadi A, Soufizadeh S. Effects of drip irrigation regimes on potato tuber yield and quality. Archives of Agronomy and Soil Science, 2013; 59(6): 889-897.

[24] Luo H, Li F S. Tomato yield, quality and water use efficiency under different drip fertigation strategies. Scientia Horticulturae, 2018; 235 : $181-188$

[25] Wang H D, Wu L F, Cheng M H, Fan J L, Zhang F C, Zou Y F, et al. Coupling effects of water and fertilizer on yield, water and fertilizer use efficiency of drip-fertigated cotton in northern Xinjiang, China. Field Crops Research, 2018; 219: 169-179.

[26] Peñuelas J, Gamon J A, Fredeen A L, Merino J, Field C B. Reflectance indices associated with physiological changes in nitrogen- and water-limited sunflower leaves. Remote Sensing of Environment, 1994; 48: 135-146.

[27] Corbeels M, Hofman G, Van Cleemput O. Residual effect of nitrogen fertilisation in a wheat-sunflower cropping sequence on a Vertisol under semi-arid Mediterranean conditions. European Journal of Agronomy, 1998; 9(2-3): 109-116.

[28] Shehzad M A, Maqsood M. Integrated nitrogen and boron fertilization improves the productivity and oil quality of sunflower grown in calcareous soil. Turkish Journal of Field Crops, 2015; 20(2): 213-222.

[29] Ge X Y, He X L, Wang Z H, Lei C X, Song C J. Influence of irrigation on water consumption character and yield of multiple seeding sunflower. Journal of Irrigation and Drainage, 2012; 31(3): 111-113. (in Chinese)

[30] Wang Z H, Zheng X R, Song C J. Effect of drip irrigation on water consumption and growth of oil sunflower in northern Xinjiang. Journal of Nuclear Agricultural Sciences, 2014; 28(5): 919-928. (in Chinese)

[31] Thierry S, Jacques G. Optimization of a nitrogen analyser based on the Dumas method. Analytica Chimica Acta, 2004; 515(1): 191-198.

[32] Panigrahi B. A handbook on irrigation and drainage. New India Publishing Agency, 2013; 620p

[33] Hou Y S, Wang Z H, Ding H J, Li W H, Wen, Y, Zhang J F, et al Evaluation of suitable amount of water and fertilizer for mature grapes in drip irrigation in extreme arid regions. Sustainability-Basel, 2019; 11(7): 2063. doi: DOI:10.3390/su1102063.

[34] Li X X, Liu H G, He X L, Gong P, Lin E. Water-nitrogen coupling and multi-objective optimization of cotton under mulched drip irrigation in arid northwest China. Agronomy-Basel, 2019; 9(12): 894. doi: 10.3390/ agronomy9120894.

[35] Liu X G, Zhang F C, Yang Q L, Li Z J, Wu L F. Effects of regulated deficit irrigation and nitrogen nutrition on validity of water and nitrogen in maize rootzone soil. Transactions of the Chinese Society of Agricultural Engineering, 2010; 26: 135-141. (in Chinese)

[36] Fan J L, Wu L F, Zhang F C, Yan S C, Xiang Y Z. Evaluation of drip fertigation uniformity affected by injector type, pressure difference and lateral layout. Irrigation and Drainage, 2017; 66(4): 520-529.

[37] Tang P, Li H, Zakaria I, Chen C. Effect of manifold layout and fertilizer solution concentration on fertilization and flushing times and uniformity of drip irrigation systems. Agricultural Water Management, 2018; 200: 71-79.

[38] Zhang J J, Li J S, Zhao B Q, Li Y T. Simulation of water and nitrogen dynamics as affected by drip fertigation strategies. Journal of Integrative Agriculture, 2015; 14(12): 2434-2445.

[39] Moraes L A C, Moreira A, Souza L G M, Cerezini P. Nitrogen sources and rates effect on yield, nutritional status, and yield components of sunflower. Communications in Soil Science and Plant Analysis, 2017; 48(14): 1627-1635.

[40] Garofalo P, Rinaldi M. Leaf gas exchange and radiation use efficiency of sunflower (Helianthus annuus L.) in response to different deficit irrigation strategies: From solar radiation to plant growth analysis. European Journal of Agronomy, 2015; 64: 88-97.

[41] Ünlü M, Kanber R, Şenyigit U, Onaran H, Diker K. Trickle and sprinkler irrigation of potato (Solanum tuberosum $\mathrm{L}$ ) in the Middle Anatolian Region in Turkey. Agricultural Water Management, 2006; 79: 43-71.

[42] Wang C, She H Z, Liu X B, Hu D, Ruan R W, Shao M B, et al. Effects of fertilization on leaf photosynthetic characteristics and grain yield in tartary buckwheat Yunqiao1. Photosynthetica, 2016; 55: 1-8.

[43] De Grazia J, Tittonell P A, Chiesa A. The effect of substrates with compost and nitrogenous fertilization on photosynthesis, precocity and pepper (Capsicum annuum) yield. Ciencia e Investigación Agraria, 2007; 34(4): 195-204.

[44] Wu X L, Li C S, Tang Y L, Liu Y B, Li B Q, Fan G Q, et al. Effect of nitrogen management modes on grain yield, nitrogen use efficiency and light use efficiency of wheat. Chinese Journal of Applied Ecology, 2017; 28(6): 1889-1898. (in Chinese)

[45] Yang D Q, Dong W H, Luo Y L, Song W T, Cai T, Li Y, et al. Effects of nitrogen application and supplemental irrigation on canopy temperature and photosynthetic characteristics in winter wheat. Journal of Agricultural Science, 2018; 156(1): 13-23.

[46] Zeng W Z, Xu C, Wu J W, Huang J S, Zhao Q, Wu M S. Impacts of salinity and nitrogen on the photosynthetic rate and growth of sunflowers (Helianthus annuus L.). Pedosphere, 2014; 24(5): 635-644.

[47] Sperling O, Karunakaran R, Erel R, Yasuor H, Klipcan L, Yermiyahu U. Excessive nitrogen impairs hydraulics, limits photosynthesis, and alters the metabolic composition of almond trees. Plant Physiology and Biochemistry, 2019; 143: 265-274.

[48] Marschner H, Marschner P. Marschner's mineral nutrition of higher plants. San Diego: Academic Press, 2012.

[49] Omondi J O, Lazarovitch N, Rachmilevitch S, Yermiyahu U, Sperling O. High nitrogen availability limits photosynthesis and compromises carbohydrate allocation to storage in roots of Manihot esculenta Crantz. Frontiers in Plant Science, 2019; 10: 1041. doi: 10.3389/fpls.2019.01041.

[50] Yang X Y, Wang X F, Wei M. Response of photosynthesis in the leaves of cucumber seedlings to light intensity and $\mathrm{CO}_{2}$ concentration under nitrate stress. Turkish Journal of Botany, 2010; 34(4): 303-310.

[51] Li K, Li H, Shi G, Xiao M, Li C R, Xie H C. Physiological responses of Scirpus validus to nitrate stress. Polish Journal of Environmental Studies, 2020; 29(1): 163-172. 
[52] Pascual M, Villar J M, Rufat J. Water use efficiency in peach trees over a four-years experiment on the effects of irrigation and nitrogen application. Agricultural Water Management, 2016; 164: 253-266.

[53] Guizani M, Dabbou S, Maatallah S, Montevecchi G, Hajlaoui H, Rezig M, et al. Physiological responses and fruit quality of four peach cultivars under sustained and cyclic deficit irrigation in center-west of Tunisia. Agricultural Water Management, 2019; 217: 81-97.

[54] Wang R D, Yin J Z. Crop cultivation science. Beijing: Higher Education Press, 2015.

[55] Pirmoradian N, Sepaskhah A R, Maftoun M. Deficit irrigation and nitrogen effects on nitrogen-use efficiency and grain protein of rice. Agronomie, 2004; 24(3): 143-153.

[56] Yu G R, Wang Q F, Zhuang J. Modeling the water use efficiency of soybean and maize plants under environmental stresses: application of a synthetic model of photosynthesis-transpiration based on stomatal behavior. Journal of Plant Physiology, 2004; 161: 303-318.

[57] Massignam A M, Chapman S C, Hammer G L, Fukai S. Physiological determinants of maize and sunflower grain yield as affected by nitrogen supply. Field Crops Research, 2009; 113(3): 256-267.

[58] Wang R, He W S, Ma Y B, Ren R, Zhao T. Effects of nitrogen fertilizer application on NPK accumulations and yield for oilseed sunflower. Chinese Journal of Oil Crop Sciences, 2014; 36(4): 494-501. (in Chinese)

[59] Li X H, He W T, Bai H B, Li N, Chen P. Characteristics of nitrogen, phosphorus and potassium uptake at different growth stages of sunflowers in Ningxia. Acta Agriculturae Boreali-occidentalis Sinica, 2009; 18(5):
$167-175$.

[60] Hocking P J, Steer B T. Effects of timing and supply of nitrogen on nitrogen remobilization from vegetative organs and redistribution to developing seeds of sunflower. Plant and Soil, 1995; 170: 359-370.

[61] Fan M T, Xu J H, Chen Y N, Li D H, Tian S S. How to sustainably use water resources-A case study for decision support on the water utilization of Xinjiang, China. Water, 2020; 12(12): 3564. doi: 10.3390/ w12123564

[62] Kiani M, Gheysari M, Mostafazadeh-Fard B, Majidi M M, Karchani K, Hoogenboom G. Effect of the interaction of water and nitrogen on sunflower under drip irrigation in an arid region. Agricultural Water Management, 2016; 171: 162-172.

[63] Wan S Q, Jiao Y P, Kang Y H, Jiang S F, Tian J L, Liu W, et al. Growth and yield of oleic sunflower (Helianthus annuus L.) under drip irrigation in very strongly saline soils. Irrigation Science, 2013; 31(5): 943-957.

[64] Rafiei H, Soleymani A, Golparvar A R. Effect of different nitrogen levels on yield components and seed yield of three sunflower (Helianthus annuus L.) cultivars. Research on Crops, 2012; 13(3): 996-1000.

[65] Nasim W, Bano A. Impact of nitrogen and plant growth promoting rhizobacteria on yield and yield components of sunflower in a glasshouse environment. Journal of Crop Science and Biotechnology, 2012; 15(4): 319-324.

[66] Zhang X D, Liu Z G, Reshalaiti M. The variation of soil physicochemical properties in farmlands with different cultivation years in oasis of Xinjiang. Research of Soil and Water Conservation, 2016; 23(3): 13-18. (in Chinese) 